\title{
EVALUATION OF TOXICOLOGICAL RESPONSES OF SOME INSECTICIDES AGAINST HELICOVERPA ARMIGERA (HÜBNER) IN LABORATORY
}

\author{
Shafia Saba', Madiha Mobeen Khan², Imran Akhtar' ${ }^{2}$, Syed Waqar Hussain Shah², Naeem Arshad Maan', Wajiha \\ Anum $^{2}$, Nadia Manzoor ${ }^{2}$, Mashal Rehman², Natasha Kanwal ${ }^{2}$ \\ ${ }^{1}$ Health Department, Multan, Pakistan. \\ ${ }^{2}$ Regional Agricultural Research institute, Bahawalpur, Pakistan.
}

\section{A R T I C L E I N F O}

\section{Article history}

Received: $2^{\text {nd }}$ February, 2019

Revised: $18^{\text {th }}$ March, 2019

Accepted: $18^{\text {th }}$ March, 2019

Keywords

Deltamethrin

Bifenthrin

Spinosad

Indoxacarb

Helicoverpa armigera
A B S T R A C T

The present study was designed to determine the $\mathrm{LC}_{50}$ of some insecticides commonly used against Helicoverpa armigera and their comparative efficacy against the insect pest. The second instar larvae of $H$. armigera reared in the laboratory were selected for leaf dip bioassay. Two types of insecticides viz. conventional (deltamethrin and bifenthrin) and new chemistry (spinosad and indoxacarb) were assessed in the present studies. The results revealed that bifenthrin was more toxic to the second instar larvae of $H$. armigera at all the doses with lower $\mathrm{LC}_{50}$ value of $120.007 \mathrm{ppm}$ as compared to deltamethrin with the highest $\mathrm{LC}_{50}$ value of 292.404 $\mathrm{ppm}$. Among the new chemistry insecticides, indoxacarb proved to be more toxic than spinosad with $\mathrm{LC}_{50}$ of $5.592 \mathrm{ppm}$. $\mathrm{LC}_{50}$ of spinosad was $8.201 \mathrm{ppm}$ showing 1.46 times less toxicity than indoxacarb.

Corresponding Author: Madiha Mobeen Khan

Email: madiha.mobeen@yahoo.com

(C) 2018 EScience Press. All rights reserved.

\section{INTRODUCTION}

American bollworm, Helicoverpa armigera, one of the chief agricultural pests, has attained the status of global circulation. It has conquered most of the parts of Asia, Australia, Africa and southern Mediterranean region including 29 cotton producers such as China, Pakistan, India and Egypt (Anonymous, 2005; Kassi et al., 2018; Kassi et al., 2019). The anticipated annual expense on the agricultural insecticides in India is $\$ 480$ million and half of which is utilized on cotton. From this total share of pesticides applied on cotton, $75 \%$ is used against $H$. armigera (Kranthi et al., 2002). In Pakistan, H. armigera emerged as a key pest of cotton and other crops in 1990s while its topical eruption was recorded in 1997 and 1998. The outburst of this insect pest resulted in complete crop failure (Ahmad et al., 1995). H. armigera has the ability to acclimatize diverse cropping systems (McCaffery, 1998). The major issues contributing to its pest status are the physiological, ethological and ecological factors which include high polyphagy, wide geographical range, mobility, migratory potential, facultative diapause, high fecundity and propensity to develop resistance to insecticides. In addition to this, an elevated level of resistance to pyrethroids and organophosphate group of insecticides had made the situation worse (Armes et al., 1996).

It is well known that the conventional classes of insecticides are detrimental for the beneficial insects and H. armigera has developed resistance against them. Therefore, it is imperative to apply insecticides which are safe and secured for the natural enemies (Nasreen et al., 2003). The new generation insecticides with novel mode 
of actions are much more discriminating as compared to the older suite of pesticides. There are a lot of new chemical compositions like spinosad, emamectin, indoxacarb, pymetrozine, diafethiuron and methoxyfenozide and biologicals e.g., NPV virus and BT sprays which have promised to be the efficient tools of IPM because of being less toxic to beneficial insects (Wilson et al., 2002).

In toxicological studies where the main concern is to find out the comparative toxicity of different chemicals on the living organisms, probit analysis is an extensively used method. The comparisons of the toxicities may produce many endpoints like $\mathrm{LC}_{50}$ (liquids) or $\mathrm{LD}_{50}$ (solids). $\mathrm{Ch}$ Tariq et al. (2005) investigated the effectiveness of Deltaphos 360 EC, Tracer 240 SC, Steward 150 EC, Emamectin 1.9 SC, Lorsban $40 \mathrm{EC}$ and Curacron $500 \mathrm{EC}$ to control $H$. armigera and found Tracer to be the most effective for the management of $\mathrm{H}$. armigera. Zahid and Hameed (2003) studied the comparative efficacy of six insecticides i.e. Larvin 80 DF, Lannate 40 SP, Lorsban 40 EC, Fastac 5 EC, Desic 10 EC and Fury-F18. The maximum effectiveness was shown by Lorsban after 72 hours followed by Larvin. Cheema et al. (2004) applied Steward 150 EC (indoxacarb) and Tracer 4.8 SC (spinosad) to control first generation of $H$. armigera on cotton. Treatments with insecticides viz. Steward and Tracer did not allow development of the pest at second generation.
Similarly, Murray et al. (2005) assessed the efficacy of some new insecticides for the control of $H$. armigera in field experiments in Australia using grain crops and reported that indoxacarb and spinosad were consistently superior to other tested products. Keeping in view the above mentioned facts, the current study was designed to determine the $\mathrm{LC}_{50}$ of some insecticides commonly used against $H$. armigera and the comparison of their efficacy using Probit analysis.

\section{MATERIALS AND METHODS}

Laboratory conditions: The experiment was conducted at Eco-Toxicology Laboratory, Department of Agricultural Entomology, University of Agriculture, Faisalabad, Pakistan. The temperature of the laboratory during experiment was maintained at $27 \pm 1^{\circ} \mathrm{C}$ whereas the photoperiod was $14: 10 \mathrm{D} / \mathrm{L}$ hours. The humidity was maintained at $65 \pm 5 \%$.

Insect pest: Helicoverpa armigera (Hübner) was collected from field area at University of Agriculture, Faisalabad in the form of fifth or sixth instar larvae. Each compilation was consisted of about 80 larvae in individual ventilated plastic vials along with the leaves of host plants. The larvae were then brought to the laboratory and transferred to individual Petri dishes.

Rearing: In the laboratory, the larvae were fed on the artificially prepared diet (Table 1) in individual Petri dishes as reported by Ahmad et al. (2003).

Table 1. Artificial diet used for feeding larvae of H. armigera.

\begin{tabular}{ccc}
\hline Sr. No. & Ingredient & Quantity \\
\hline 1 & Water & $500 \mathrm{ml}$ \\
2 & Agar & $8.5 \mathrm{ml}$ \\
3 & Chick pea Powder & $150 \mathrm{~g}$ \\
4 & Ascorbic acid & $2.35 \mathrm{~g}$ \\
5 & Sorbic acid & $0.75 \mathrm{~g}$ \\
6 & Yeast & $24 \mathrm{~g}$ \\
7 & Methyl-para-hydroxy benzoate & $3.5 \mathrm{~g}$ \\
8 & Streptomycin & $0.75 \mathrm{~g}$ \\
9 & Vitamin mixture & $5 \mathrm{ml}$ \\
10 & Corn oil & $6 \mathrm{ml}$ \\
\hline
\end{tabular}

All the ingredients except agar, vitamin solution and corn oil were mixed thoroughly along with half distilled water in a blender. The remaining half of the water was boiled; agar was added slowly by continuous stirring and then was added to hot solution into the blender containing other ingredients. The ingredients were again mixed thoroughly and corn oil and vitamin solution were added.
The diet was poured in a flat bowl, allowed to cool for one hour at room temperature and stored in the refrigerator. To get homogenous population for the experiment, the prepared diet was fed to the larvae daily in the glass jars. After $3^{\text {rd }}$ instar, the larvae were transferred to separate Petri dishes to avoid cannibalism and diet was provided separately in all the Petri dishes. The Petri dishes were 
replaced daily to avoid contamination. The larvae were kept in Petri dishes and fed with the artificial diet until the $6^{\text {th }}$ instar after which they showed sluggish behavior and transformed into pupae. The pupae were then transferred to a separate chamber.

Adults emerged in 12-14 days were transferred to adult rearing plastic cages. Ten per cent honey solution in water (soaked cotton pads) was fed to adults. After 4 days, a piece of nappy liner, was hung inside the jar in order to collect eggs laid by female moths. The eggs were harvested daily and transferred to glass jars containing semi synthetic diet. The larvae emerged and the $2^{\text {nd }}$ instar larvae were used for testing the efficacy.

Insecticides: The insecticides given in Table 2 were assessed for their toxicity against $H$. armigera by using Probit Analysis in laboratory.

Table 2. Detail of insecticides assessed against H. armigera.

\begin{tabular}{llll}
\hline Trade name & Formulations & Active ingredient & Manufacturer \\
\hline Capture & $10 \mathrm{EC}$ & Bifenthrin & FMC corporation \\
Decis Super & $20 \mathrm{EC}$ & Deltamethrin & Bayer crop sciences, Montpellier, France \\
Steward & $150 \mathrm{SC}$ & Indoxacarb & DuPont,Wilmington, DE, USA \\
Tracer & $240 \mathrm{SC}$ & Spinosad & Dow Agro Sciences \\
\hline
\end{tabular}

Bioassay: Second instar larvae of H. armigera, reared in the laboratory, were selected for bioassay. The leaf dip bioassay method recommended by the Insecticide Resistance Action Committee (IRAC) was used for the efficacy evaluation of the test insecticides (Anonymous, 1990).

The formulations of the active ingredients of test chemicals were prepared in ppm using tap water with the help of micro pipette. For every test insecticide, six successive concentrations were prepared in glass jars. Fresh unsprayed leaves of the host plants were cut into leaf discs of $5 \mathrm{~cm}$ diameter. The sliced leaves were immersed into the beaker containing the test solutions for 10 seconds with the help of forceps and allowed to surface dry on a paper towel. The leaf discs were then placed into $5 \mathrm{~cm}$ diameter Petri-dishes. The Petri dishes contained filter papers, moistened with water using a dropper to avoid desiccation of leaves. Five $2^{\text {nd }}$ instar laboratory reared larvae were placed onto each leaf disc which was then placed in a Petri dish with a fine camel hair brush. After releasing the larvae, Petri dishes were covered with plastic lids to keep the whole lot under controlled environmental conditions. There were six replicates of five larvae for each concentration. The same numbers of leaf discs for every treatment were dipped into distilled water as an untreated check. The larvae were maintained at a constant temperature before and after the treatment.

Following formula was used to convert ppm into $\mu \mathrm{l}$ :

$$
\begin{aligned}
\mu \mathrm{l}=\frac{\text { ppm required } \times \text { Volume of solvent (Water) used }}{} \\
\times 10
\end{aligned}
$$

Statistical analysis: Mortality was assessed after 48 and 72 hours for conventional and new chemistry insecticides respectively. Insects were considered dead if they gave no reaction to stimulus by touch. Percentage mortality was calculated and data were analyzed using probit analysis (Finney, 1971) with the software POLO-PC (Anonymous, 1987).

\section{RESULTS}

The toxicological effects of test insecticides against second instar larvae of $H$. armigera are given in table 3 and 4. It is clear from the data given in tables 3 and 4 that larvae of $H$. armigera showed significant variations in their responses to selected insecticides.

Efficacy of deltamethrin and bifenthrin against second instar larvae of $\boldsymbol{H}$. armigera: Among pyrethroides, bifenthrin proved to be more toxic to $2^{\text {nd }}$ instar larvae of $H$. armigera with lower $\mathrm{LC}_{50}$ (120.007) at $1024 \mathrm{ppm}$ as compared to deltamethrin with higher $\mathrm{LC}_{50}$ of 292.404 at same concentration. The $\mathrm{LC}_{50}$ of deltamethrin was 2.42 times greater than that of bifenthrin.

Bifenthrin was found to be more toxic to the $2^{\text {nd }}$ instar larvae of H. armigera at all the doses. Deltamethrin caused $86.7 \%$ mortality at $1024 \mathrm{ppm}$ as against $93.4 \%$ caused by bifenthrin at the same dose. Similarly, the mortality at $512 \mathrm{ppm}$ was 53.4 and $83.4 \%$ with deltamethrin and bifenthrin respectively. The percent mortalities caused by deltamethrin and bifenthrin at other concentrations are given in table 3.

Efficacy of indoxacarb and spinosad against second instar larvae of $\boldsymbol{H}$. armigera: Indoxacarb proved to be 
more toxic as compared to spinosad with $\mathrm{LC}_{50}$ of 5.592 at a concentration of $64 \mathrm{ppm}$. Similarly, $\mathrm{LC}_{50}$ by spinosad was 8.201 at the same concentration showing 1.46 times less toxicity to indoxacarb. Both the new chemistry insecticides caused $100 \%$ mortality of $2^{\text {nd }}$ instar larvae of
H. armigera at $64 \mathrm{ppm}$. At a concentration of $32 \mathrm{ppm}$, indoxacarb caused $100 \%$ mortality while spinosad caused $86.7 \%$ mortality at the same dose. The percent mortalities caused by spinosad and indoxacarb at other doses are shown in table 4 .

Table 3. Comparative toxicity of deltamethrin and bifenthrin against $2^{\text {nd }}$ instar larvae of $H$. armigera.

\begin{tabular}{|c|c|c|c|c|c|c|c|c|}
\hline \multirow[t]{2}{*}{ Insecticide } & \multirow{2}{*}{$\begin{array}{l}\text { Dose } \\
\text { ppm }\end{array}$} & \multirow[t]{2}{*}{$\mathrm{n}^{\mathrm{a}}$} & \multirow[t]{2}{*}{$r^{b}$} & \multirow[t]{2}{*}{$\mathrm{m}^{\mathrm{c}}$} & \multirow[t]{2}{*}{ Slope \pm SE } & \multirow[t]{2}{*}{$\mathrm{LC}_{50}$} & \multicolumn{2}{|c|}{ 95\% FLC of LC } \\
\hline & & & & & & & Lower & Upper \\
\hline \multirow[t]{7}{*}{ Deltamethrin } & 1024 & 30 & 26 & 86.7 & $1.284 \pm 0.212$ & 292.404 & 174.811 & 595.506 \\
\hline & 512 & 30 & 16 & 53.4 & & & & \\
\hline & 256 & 30 & 12 & 40.0 & & & & \\
\hline & 128 & 30 & 09 & 30.0 & & & & \\
\hline & 64 & 30 & 07 & 23.4 & & & & \\
\hline & 32 & 30 & 04 & 13.4 & & & & \\
\hline & 00 & 30 & 01 & 3.34 & & & & \\
\hline \multirow[t]{7}{*}{ Bifenthrin } & 1024 & 30 & 28 & 93.4 & $1.432 \pm 0.219$ & 120.007 & 82.366 & 166.363 \\
\hline & 512 & 30 & 25 & 83.4 & & & & \\
\hline & 256 & 30 & 19 & 63.4 & & & & \\
\hline & 128 & 30 & 14 & 46.7 & & & & \\
\hline & 64 & 30 & 11 & 36.7 & & & & \\
\hline & 32 & 30 & 07 & 23.4 & & & & \\
\hline & 00 & 30 & 00 & 0.00 & & & & \\
\hline
\end{tabular}

a= No. of larvae exposed, b= No. of Larvae died, c=Percent mortality, d=Fucidial limit

Table 4. Comparative toxicity of spinosad and indoxacarb against $2^{\text {nd }}$ instar larvae of $H$. armigera.

\begin{tabular}{|c|c|c|c|c|c|c|c|c|}
\hline \multirow[t]{2}{*}{ Insecticide } & \multirow{2}{*}{$\begin{array}{l}\text { Dose } \\
\text { ppm }\end{array}$} & \multirow[t]{2}{*}{$\mathrm{n}^{\mathrm{a}}$} & \multirow[t]{2}{*}{$r^{b}$} & \multirow[t]{2}{*}{$\mathrm{m}^{\mathrm{c}}$} & \multirow[t]{2}{*}{ Slope \pm SE } & \multirow[t]{2}{*}{$\mathrm{LC}_{50}$} & \multicolumn{2}{|c|}{ 95\% FLC of LC } \\
\hline & & & & & & & Lower & Upper \\
\hline \multirow[t]{7}{*}{ Spinosad } & 64 & 30 & 30 & 100 & $2.008 \pm 0.319$ & 8.201 & 5.481 & 11.168 \\
\hline & 32 & 30 & 26 & 86.7 & & & & \\
\hline & 16 & 30 & 21 & 70.0 & & & & \\
\hline & 08 & 30 & 15 & 50.0 & & & & \\
\hline & 04 & 30 & 08 & 26.7 & & & & \\
\hline & 02 & 30 & 06 & 20.0 & & & & \\
\hline & 00 & 30 & 01 & 3.34 & & & & \\
\hline \multirow[t]{7}{*}{ Indoxacarb } & 64 & 30 & 30 & 100 & $2.317 \pm 0.348$ & 5.592 & 3.993 & 7.317 \\
\hline & 32 & 30 & 30 & 100 & & & & \\
\hline & 16 & 30 & 24 & 80 & & & & \\
\hline & 08 & 30 & 18 & 60 & & & & \\
\hline & 04 & 30 & 13 & 43.4 & & & & \\
\hline & 02 & 30 & 06 & 20 & & & & \\
\hline & 00 & 30 & 01 & 3.34 & & & & \\
\hline
\end{tabular}

$\mathrm{a}=$ No. of larvae exposed, $\mathrm{b}=$ No. of Larvae died, $\mathrm{c}=$ Percent mortality, $\mathrm{d}=$ Fucidial limit 
Efficacy of indoxacarb and spinosad against second instar larvae of $\boldsymbol{H}$. armigera: Indoxacarb proved to be more toxic as compared to spinosad with $\mathrm{LC}_{50}$ of 5.592 at a concentration of $64 \mathrm{ppm}$. Similarly, $\mathrm{LC}_{50}$ by spinosad was 8.201 at the same concentration showing 1.46 times less toxicity to indoxacarb. Both the new chemistry insecticides caused $100 \%$ mortality of $2^{\text {nd }}$ instar larvae of H. armigera at $64 \mathrm{ppm}$. At a concentration of $32 \mathrm{ppm}$, indoxacarb caused $100 \%$ mortality while spinosad caused $86.7 \%$ mortality at the same dose. The percent mortalities caused by spinosad and indoxacarb at other doses are shown in table 4.

\section{DISCUSSION}

In the present study, deltamethrin proved less toxic to the larvae of $H$. armigera with highest $\mathrm{LC}_{50}$ value of 292.404 at $1024 \mathrm{ppm}$. This indicates the development of resistance in $H$. armigera against deltamethrin. Bifenthrin with lower $\mathrm{LC}_{50}$ value of 120.007 at the same ppm was approximately 2.5 times more toxic than deltamethrin. The results are in conformity with those of Manikandan (1998) who reported high level of resistance to deltamethrin in $H$. armigera. Denholm and Rowland (1992) reported the resistance to pyrethroids from Thailand, Zimbabwe, Indonesia, Egypt, and India. The results are also in concurrence with those of Torres-Vila et al. (2002) whose findings proved that deltamethrin is superior to bifenthrin. In the study, they noticed that $\mathrm{LC}_{50}$ of bifenthrin was $0.04 \mu \mathrm{g} /$ larvae while that of deltamethrin was $1.01 \mu \mathrm{g} / \mathrm{larvae}$. Martin et al. (2003) reported $\mathrm{LD}_{50}$ of deltamethrin to be $104.8 \mu \mathrm{g}$ against $H$. armigera larvae. Aheer et al. (2009) checked the effect of bifenthrin on 11 field strains of $H$. armigera and observed $\mathrm{LC}_{50}$ values ranging from $24.18 \mathrm{ppm}$ to $60.60 \mathrm{ppm}$.

Indoxacarb was more toxic with $\mathrm{LC}_{50}$ of 5.592 at $64 \mathrm{ppm}$ which is 1.46 times more toxic than spinosad with $\mathrm{LC}_{50}$ value of 5.481 at the same concentration. The results are in accordance with those reported by Rahman et al. (2006) who found that Steward 150 EC was the most persistent insecticide against $H$. armigera (Hub.) on gram (chickpea) and caused the highest mortality of $97.88 \%$ while in the same experiment Tracer 240 SC caused 93.02\% mortality. Nisar (2004) tested the efficacy of different insecticides against $H$. armigera on apple and found Steward $150 \mathrm{EC}$ to be the most effective insecticide with maximum pest mortality of $84.43 \%$ and $86.89 \%$ in two locations of Swat valley. Aheer et al. (2009) checked the effect of spinosad and indoxacarb on 11 field strains of $H$. armigera and observed $\mathrm{LC}_{50}$ values ranging from
$2.31 \mathrm{ppm}$ to 11.47 for indoxacarb and $0.28 \mathrm{ppm}$ to 0.86 ppm for spinosad. These findings are in contrast with those reported in the present studies.

\section{REFERENCES}

Aheer, G.M., Aziz, M.A., Hameed, A., Ali, A., 2009. Evaluation of resistance to different insecticides in field strains of Helicoverpa armigera (Lepidoptera: Noctuidae) in Punjab, Pakistan. Entomological Research 39, 159-167.

Ahmad, M., Arif, I.M., Ahmad, Z., 1995. Monitoring insecticide resistance of Helicoverpa armigera (Lepidoptera: Noctuidae) in Pakistan. Journal of Economic Entomology 88, 771-776.

Ahmad, M., Arif, M.I., Ahmad, Z., 2003. Susceptibility of Helicoverpa armigera (Lepidoptera: Noctuidae) to new chemistries in Pakistan. Crop Protection 22, 539-544.

Anonymous, 1987. A user Guide to Probit or Logit Analysis, Le Ora Software, Berkeley, CA, USA.

Anonymous, 1990. Proposed insecticide/acaricide susceptibility tests, IRAC method No. 7. EPPO Bulletin 20, 389-404.

Anonymous, 2005. Distribution maps of quarantine pests, Helicoverpa armigera. Prepared by CABI and EPPO for the EU under Contract 90/399003.

Armes, N.J., Jadhav, D.R., DeSouza, K.R., 1996. A survey of insecticide resistance in Helicoverpa armigera in the Indian subcontinent. Bulletin of Entomological Research 86, 499-514.

Ch Tariq, M., Malik, M.A., Iqbal, N., 2005. Management o Helicoverpa armigera with different insecticides. Pakistan Journal of Agricultural Sciences 42, 75-77.

Cheema, G.M., Nasreen, A., Ashfaq, M., 2004. Application of selective insecticides to control first generation of Helicoverpa armigera (Hübner) on cotton. Pakistan Entomologist 26, 35-37.

Denholm, I., Rowland, M.W., 1992. Tactics for managing pesticide resistance in Arthropods: Theory and Practice. Annual Review of Entomology 37, 91-112.

Finney, D.J., 1971. Probit Analysis, 3rd ed. Cambridge University Press, UK.

Kassi, A.K., Javed, H., Mukhtar, T., 2018. Screening of okra cultivars for resistance against Helicoverpa armigera. Pakistan Journal of Zoology 50, 91-95.

Kassi, A.K., Javed, H., Mukhtar, T., 2019. Relationship of physico-morphic characters of okra cultivars with their resistance to Helicoverpa armigera. Pakistan Journal of Zoology 51, 835-841. 
Kranthi, K.R., Jadhav, D.R., Kranthi, S., Wanjari, R.R., Ali, S.S., Russell, D.A., 2002. Insecticide resistance in five major insect pests of cotton in India. Crop Protection 21, 449-460.

Manikandan, P., 1998. Comparative resistance of Heliothis armigera populations to some insecticides in different places of Tamil Nadu. Insect Environ 4, 9-10.

Martin, T., Ochou, O.G., Vaissayre, M., Fournier, D., 2003. Organophosphorus Insecticides Synergize Pyrethroids in the Resistant Strain of Cotton Bollworm, Helicoverpa armigera (Hübner) (Lepidoptera: Noctuidae) from West Africa. Journal of Economic Entomology 96, 468-474.

McCaffery, A.R., 1998. Resistance to insecticides in Heliothine Lepidoptera: a global view. Philosophical Transactions of the Royal Society of London. Series B: Biological Sciences 353, 17351750 .

Murray, D.A.H., Lloyd, R.J., Hopkinson, J.E., 2005. Efficacy of new insecticides for management of Helicoverpa spp. (Lepidoptera: Noctuidae) in Australian grain crops. Australian Journal of Entomology 44, 62-67.

Nasreen, A., Mustafa, G., Ashfaq, M., 2003. Selectivity of Some Insecticides to Chrysoperla carnea (Stephen)
(Neuroptera: Chrysopidae) in Laboratory. Pakistan Journal of Biological Sciences 6, 536-538.

Nisar, J., 2004. Management of Helicoverpa armigera (Hub.) on apple in Swat valley, Department of Plant Protection. NWFP Agriculture University Peshawar.

Rahman, A.U., Saeed, M.Q., Jan, N., Ahmad, M., Tahir, M., 2006. Efficacy of some new insecticides against gram pod borer Helicoverpa armigera (Hub.) in Peshawar. Sarhad Journal of Agriculture 22, 293295.

Torres-Vila, L.M., Rodríguez-Molina, M.C., LacasaPlasencia, A., Bielza-Lino, P., 2002. Insecticide resistance of Helicoverpa armigera to endosulfan, carbamates and organophosphates: the Spanish case. Crop Protection 21, 1003-1013.

Wilson, L., Mensah, R., Dillon, M., Wade, M., Scholz, B., Murray, D., Heimoana, V., Lloyd, R., 2002. Impact of insecticides and miticides on predators in cotton. Australian Cotton Research 1, 1-2.

Zahid, M., Hameed, M., 2003. Comparative efficacy of insecticides against the American bollworm, Helicoverpa armigera "Hub." of cotton. Songklanakarin Journal of Science and Technology $25,169-173$. 